\title{
EVENT HORIZON
}

A bitter pill.

\section{BY JEFF HECHT}

$\mathrm{T}$ he sad eyes of the well-dressed, neatly trimmed man looked oddly familiar, but it was his question that gave him away. "Found any little green men lately?"

Alexa couldn't believe it until she glanced at his convention badge. "Karl! It's been ages!" He had been scrawny and scruffy when they did astrobiology postdocs together a quarter-century ago.

"What are you doing now?" She had lost track of him after she landed a tenure-track job.

"I gave up searching," he said, the sadness in his voice matching that in his eyes.

"What happened to your models of how advanced civilizations would develop?"

"I never published anything," he said. "After the fellowship fell through, I got a job building computer models of economic trends. It pays the bills. I talked about longterm market models here at the Futures conference."

"Oh?" Alexa hadn't noticed his name.

"It was in the business sessions. I wouldn't expect you to notice. I saw you were in the far-future session, so I decided to come. I owe you something."

Alexa looked at him blankly.

"I didn't think you would remember. We bet a meal on who would get a job first. When you did, I was too broke to take you to McDonald's. I can afford a nice dinner now, and I want to hear what you're doing."

"That would be great," Alexa said. With no travel budget and another big jump in her medical insurance, she had been about to skip dinner.

"What's surprising is that so many factors in the Drake equation are so favourable for extraterrestrial intelligence," Alexa said, enjoying the restaurant's ambience. "Remember how the first hot Jupiters were so exciting when we were postdocs? Now we've got tens of thousands of terrestrial planets in habitable zones. There has to be life out there." She paused to sip the wine, a vintage that she never could have afforded.

"But where are the

\section{$\rightarrow$ NATURE.COM}

Follow Futures on

Facebook at:

go.nature.com/mtoodm little green men?” Karl asked.

"They're out there, but we haven't found them yet. No signals at radio or optical frequencies. Maybe they're sending something we can't detect, neutrinos or particles we'll never know about until they turn the colliders back on."

"What are the odds on intelligence?"

"Once you get multicellular animals, models show intelligence is likely in a few

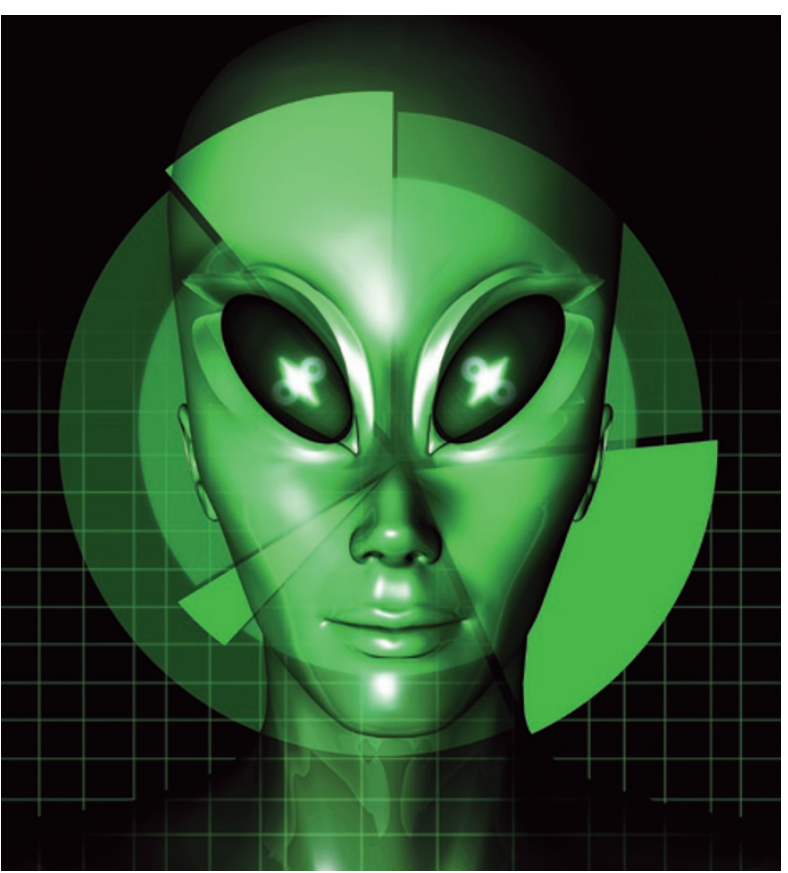

hundred million years. Technology just needs hands. Dolphins and elephants are out of luck, but bears could do it. Maybe squirrels would have a chance."

"But how long can technological civilizations last? We haven't blown ourselves up yet, but our resources are going up in smoke, and we have fouled the nest badly. How much of your annual carbon allowance did you burn getting here?"

"We don't need to visit other worlds. Sending laser or radio-frequency signals uses hardly any energy compared with interstellar travel. Anybody within 90 light years can listen to old broadcasts of The Lone Ranger."

"But that isn't free. Who'll pay the bills when the foundations go broke?" Karl set down his wine glass. "My models tell me where the money is going. Do you know what's the fastest-growing part of the economy?"
"Climate controls and energy?" Alexa guessed.

Karl shook his head. "Health care. It hit $32 \%$ of the US gross domestic product last year. It was only $5 \%$ in 1960 . That's a sixfold increase in fraction of the GDP in 70 years, and the economy has expanded a factor of 100 over that time, so dollar spending is up a factor of 600."

Alexa thought of her insurance bill. "But medicine has improved tremendously. We conquered polio and measles, and we can manage diabetes. Life expectancy is longer than ever."

"Barely," Karl muttered. "The marginal return on investment has been declining for decades." He slipped a mobile from his pocket and flashed a chart on the tablecloth with its nanoprojector. A line labelled 'life expectancy' levelled off, but one marked 'medical spending' rose exponentially.

"What does that mean?"

"The economy is approaching a medical event horizon. Better technology makes other products cheaper with time, but medicine has hit fundamental limits. Instead of buying more and more, each health-care dollar buys less and less. Companies advertise instant muscle tone-ups while you watch $3 \mathrm{D}$, and people buy them although they aren't nearly as good as exercise. Our economy is spiralling into a black hole; all new resources go into health care. NASA can't get a penny for the 15-metre space telescope."

"But that's just a temporary delay until we can work out the budget deficit."

"You can dream," Karl said. "But that's how any advanced civilization will behave. It's entirely rational for intelligent beings to try to maintain their own health and extend their own lifetimes. China slashed human space exploration to fund better health care. Little green men will do the same, so they will never land on the White House lawn."

"But we can still listen for them," Alexa protested.

"You can try," Karl sighed. "Maybe one of our neighbours in the Galaxy will broadcast their version of The Lone Ranger long enough for us to hear it." -

Jeff Hecht is Boston correspondent for New Scientist and a contributing editor to Laser Focus World. 